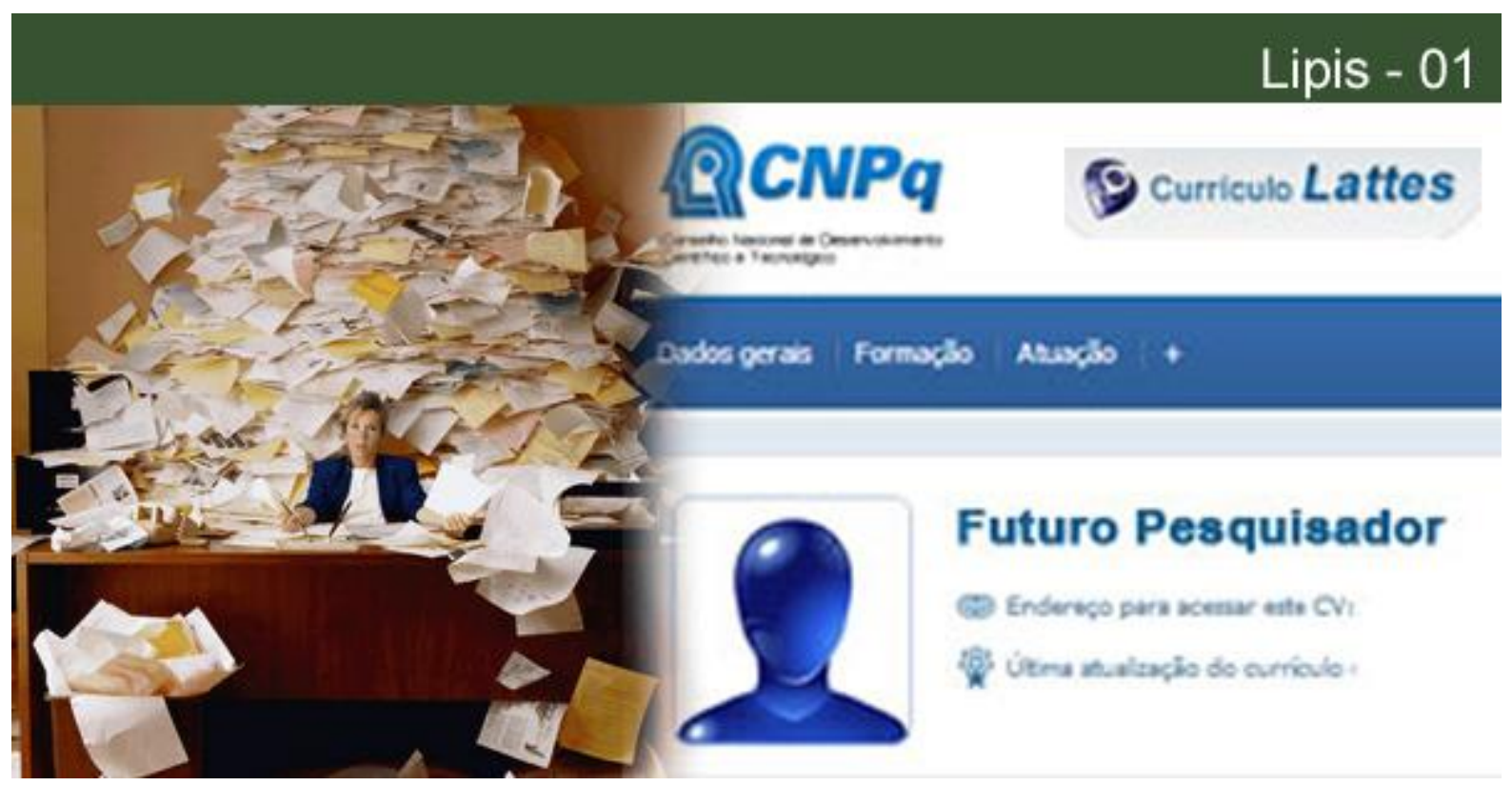

\title{
VISIBILIDADE, PRODUTIVISMO, MERCANTILIZAÇÃO E A MORTE DO PENSAMENTO: A UNIVERSIDADE SITIADA
}

\section{Lana Veras}

Psicóloga, Doutora em Psicologia Social-UERJ, Professora Adjunta dos Cursos de Psicologia e Medicina da Universidade Federal do Piauí-UFPI. E-mail: lanaveras@hotmail.com.

\section{Joelmir Portela}

Graduando em Psicologia pela Universidade Federal do Piauí, Bolsista do Programa de Educação pelo Trabalho para a Saúde-PET-Saúde Redes de Atenção.

Resumo: A lógica de gestão empresarial chega às universidades enfrentando escassas resistências. O espaço historicamente relacionado ao pensar crítico e à construção de reflexões e saberes é ocupado pelo produtivismo e pela mercantilização. A ênfase da avaliação da produção científica recai sobre a dimensão quantitativa, deixando à sombra critérios valorizados outrora. Buscando uma visibilidade performática, os pesquisadores e as instituições têm sido ranqueadas e colocadas na posição de produto de consumo. Discursos são gerados a respeito das formas de produzir pesquisa, conhecimento e reflexão na academia contemporânea. Discursos que alicerçam práticas que transformam o espaço do pensar crítico em lugar de reprodutibilidade esvaziada de algum sentido que não seja o de mercado.

Palavras-chave: Universidade. Mercantilização. Plataforma lattes.

\section{VISIBILITY, PRODUCTIVISM, MERCANTILIZATION AND THE DEATH OF THOUGHT: THE BESIEGED UNIVERSITY}

Abstract: The business management logic comes to universities facing scant resistance. The space historically related to critical thinking and the construction of reflexions and knowledges has being occupied by the productivism and the marketization. The emphasis of the evaluation of scientific production lies on the quantitative dimension, obscuring criteria in former times valued. Seeking a performative visibility, researchers and institutions have been ordered in a ranking and placed in a consumer product position. Discourses are generated in concern to the manners of producing researches, knowledge and reflexions in contemporary academy. Discourses that substantiates practices that transform the place of critical thinking into a space of reproductivity emptied of meaning other than the merchant one.

\section{POLÊM!CA | Revista Eleroroica da Uerj}


Keywords: University. Mercantilization. Lattes platform.

Figura - 1: Registro de Pichação em espaço público

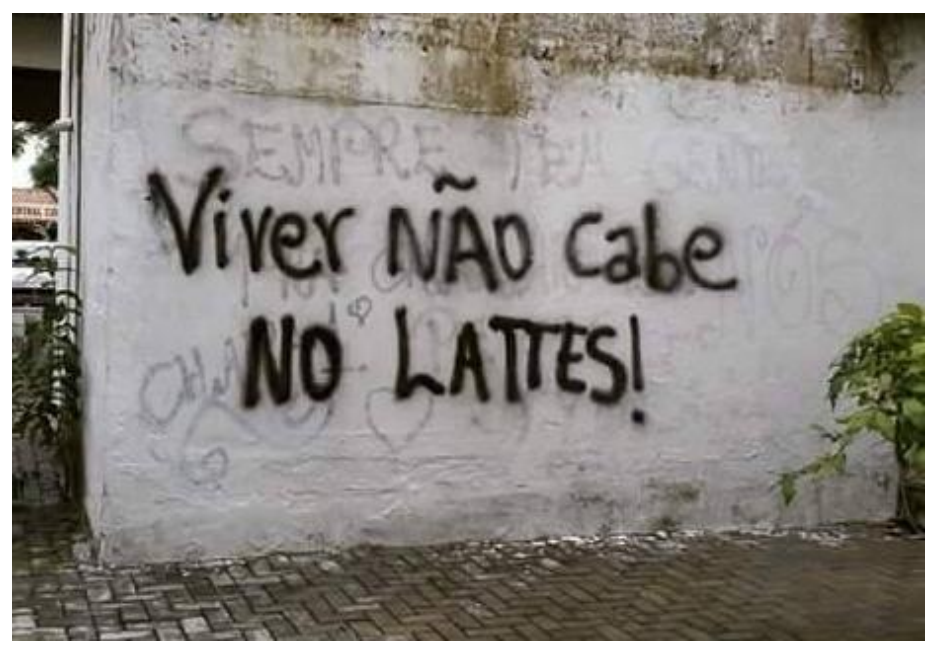

Fonte: Disponível em: <https://www.pinterest.com/pin/124974958386162386/>.

"Viver Não Cabe No Lattes". A fotografia de um muro com essa inscrição foi compartilhada nas plataformas digitais por algumas pessoas que ainda resistem à "Universidade Operacional", como a filósofa Marilena Chauí denominou o atual estado da IES brasileiras (Chauí, 2015), percebidas aqui como abocanhadas pela lógica da produtividade, do mercado, da espetacularização e da performance.

Perdendo preciosos minutos, afinal "tempo é dinheiro", em que poderiam estar submetendo mais um artigo repetitivo, burocrático, feito em série e com coautorias "alaranjadas", alguns dos pesquisadores que divulgavam a referida frase em suas redes sociais digitais perguntavam-se, com ironia: "Mas é vida Indicador 1(um) ou não? - Não... minha vida está mais para Qualis B3..."

Ao "ranquear", classificar e avaliar instituições de ensino, programas de pósgraduação, publicações e pessoas, a lógica utilizada não tem priorizado competências valorizadas no meio acadêmico e intelectual de outrora, como capacidade reflexiva, pensamento crítico e criação de novas possibilidades. A reprodução, nas universidades, dos modos de fazer de organizações comerciais incentiva a produtividade esvaziada de sentido, o império do quantitativo, a corrida vital, "currículum vitae”, pelo pódio.

Em uma sociedade que cultua a performance (EHRENBERG, 2010), não é suficiente estar desempenhando seu papel como colaborador na construção do saber, é imperativo que 
você seja o melhor, que se destaque nessa corrida pela primeira colocação. Mas qual o papel do professor/pesquisador/cientista/aluno? Quais critérios têm sido utilizados para valorizar, financiar e promover certos grupos em detrimento de outros? A dimensão do culto da performance, que vivenciamos atualmente, coloca em cena a compreensão de que, se já estamos bem, porque não melhorar? O conceito do "melhor que bem" potencializa a competição e ao mesmo tempo cria engodos, posto que pouco se tem perguntado: o que é o bem? O bem para quem? O que é bom? O que eu considero bom serve a quem?

Essa acirrada competição, essa busca por constante perfeição e volumosos currículos está em sua maioria, ligada à nova e forte cultura empresarial, como diz Bendassolli (2004), essa nova cultura está diretamente ligada a uma visão meritocrática e ao culto da performance, onde os indivíduos devem se tornar integralmente responsáveis por suas próprias carreiras, destino e sucesso, ou seja, auto gerenciar todos os aspectos da vida, onde o fracasso não é permitido.

Ehrenberg (2010) traz dois modos como o sujeito de hoje se orienta e se inspira, modos que substituem o papel tradicional da cultura, são eles: a empresa e o esporte. Originando um viver performático, por vezes cenográfico, tão evidente na atualidade. Ainda segundo esse autor, a sociedade ocidental mudou, com o passar das últimas três décadas, o modo como vê a empresa, que deixou de ser vista como local de exploração, símbolo máximo do capitalismo de concentração de renda, para se transformar em um modelo a ser imitado com êxito na vida pessoal de cada um.

O mesmo acontece com o mundo esportivo, hoje conduzido, antes de tudo, como negócios. As empresas se baseiam em modelos comuns que regem a competição esportiva para, com isso, "vencer os adversários".

Tal como em empresas e/ou nos esportes, em que os lucros, rendimentos e esforços são mensurados por gráficos, os trabalhos cadastrados na plataforma Lattes também são assim equacionados, por quantidade de trabalhos em dadas áreas, capítulos em livros, palestras, cursos, oficinas, entre outros tantos artifícios usados como sinônimo de excelência acadêmica. A lógica é iluminar a produção quantitativa, sombreando os aspectos qualitativos da obra acadêmica, que envolve uma dimensão de tempo e reflexão crítica que não são estrategicamente interessantes na construção de um "portifólio" de um profissional de sucesso.

\section{POLÊM!CA | Revista Eletronica da Uej}


Se, conforme relata Chauí (2015), "a universidade brasileira submeteu-se à ideologia neoliberal da sociedade de mercado" e transforma direitos sociais em serviços regidos pelas leis de mercado, teremos que, com a filósofa, resgatar as reflexões realizadas pelos autores da chamada "Escola de Frankfurt", quando estes afirmavam que estávamos vivendo em uma sociedade do controle esquadrinhado, uma sociedade totalmente administrada, já observava Adorno (2001, p.50), em sua obra: Mínima Morália: reflexões sobre a vida lesada.

Adorno compreendia uma sociedade emancipada não pela sua uniformidade, mas pela conciliação de suas diferenças. Porém, o que temos hoje é a determinação cada vez mais rígida de uma única direção a seguir, as várias novas possibilidades que a contemporaneidade nos apresenta não são senão facetas do mesmo Homem Unidimensional já descrito por Marcuse (1973) em: A Ideologia da Sociedade Industrial. Podemos notar que a dimensão que se configura como preponderante continua sendo a do capital e a do mercado. Marcuse se preocupava com a vinculação entre tecnologia e poder e cunhou a expressão "Sociedade Unidimensional" para demonstrar como o homem é controlado por esse modelo que enfatiza a racionalidade tecnológica e tolhe sua capacidade crítica. Esse processo leva à alienação do indivíduo, que passa a existir em apenas uma dimensão de pensamentos, comportamentos, aspirações e projetos (MARCUSE, 1973).

A "Universidade Operacional", utilizando a terminologia de Chaú, tenta se adequar a um projeto de modernidade em crise, já falido. A crise do projeto civilizatório da modernidade foi discutida por Sergio Paulo Rouanet (1993) em sua publicação Mal-estar na modernidade. Segundo o autor, esse projeto visava a auto-emancipação de uma sociedade a partir de valores e ideais ligados ao racionalismo, ao individualismo e ao universalismo refletidos nas esferas econômica, política e social, porém esse projeto entrou em colapso.

Apesar da crise dos ideais da modernidade, alguns teóricos contemporâneos compreendem que seus principais alicerces não se modificaram na contemporâneidade, pelo contrário, eles teriam sido inflacionados, gerando um momento denominado "Hipermoderno", período descrito como o nascimento de uma nova modernidade que enfatiza o movimento e cultua a modernização técnica. O sufixo hiper sugere que exista uma exacerbação de formas já existentes na modernidade e não sua total ultrapassagem, entrando na esfera do mais e do mais rápido. Uma de suas facetas seria a febre da brevidade e a generalização do reino da urgência (LIPOVETSKY \& CHARLES, 2004, p.77).

\section{POLÊM!CA | Revista Eletronica da Uerj}


O filófoso Bauman faz reflexões que caminham ao encontro do pensamento de Lipovetsky, afirmando que a sociedade do início do século XXI não é menos moderna que a do século XX, mas tão somente moderna de uma forma diferente. Pois continua a ênfase na produtividade e competitividade. As modificações se situam no esfacelamento das ilusões modernas de que a perfeição pudesse ser alcançada no futuro; e no crescente individualismo (BAUMAN, 2001, p.36). A perspectiva é de estarmos vivendo uma segunda modernidade, fundamentada nos pilares estruturais da própria modernidade, quais sejam: o mercado, a técnica e o indivíduo (SOARES, 2006).

Um ponto em que observamos uma diferença fundamental para o tema de nosso artigo é a transição do foco na produção para um foco no consumo. Com o objetivo de alavancar o consumo a sociedade investe no aumento da demanda a partir a mercantilização de áreas antes não vendáveis.

Dentro da lógica de uma sociedade de consumidores, o processo de mercantilização não acontece somente em relação a objetos e serviços, mas se estende a subjetividades e a pessoas. A transformação das pessoas em mercadoria, subtítulo de publicação do filósofo Bauman (2008, p.26), nos treinaria tanto para a escolha de produtos que mais nos atraem, como na anexação de atrativos em nós mesmos na condição de produtos à escolha dos outros. No processo de se expor, somos orientados a que características nossas podem mais interessar ao mercado de empregos ou aos nossos parceiros em relacionamentos afetivos e sexuais, ou seja, aos nossos consumidores (VERAS \& ROSA, 2015).

$\mathrm{Na}$ linguagem mercadológica, as constantes atualizações quantitativas ao currículo, “agregam valor" a nós mesmos como produtos profissionais. Bauman (2008, p.76) tratou desta questão apontando o processo de comodificação das pessoas: "Os membros da sociedade de consumo são eles próprios mercadorias de consumo, e é a qualidade de ser uma mercadoria de consumo que os torna membros autênticos dessa sociedade”.

Diante da constatação de que a lógica do mercado de consumo e da gestão de organizações chega à universidade sem sofrer muitas restrições ou resistências, assistimos à transformação dos pesquisadores, professores e alunos em espécie de comodities, que tem seu valor aumentado ou diminuído no ranking dos valores de mercado, avaliados quantitativamente. Fato nitidamente vivenciado por um dos autores deste artigo quando foi apresentada aos alunos de uma IES não como a nova professora, mas como a "nova

\section{POLÊM!CA | Revista Eletronica da Ueij}


aquisição" que tal instituição havia feito! A coordenação falou com orgulho à sua plateia de estudantes/clientes: “Aqui nós não apenas contratamos professores, nós fazemos aquisições”, pareceu-me claro que ser apresentava de tal maneira me alçava, na compreensão da instituição, a um patamar superior ao de professora.

\section{Plataforma Lattes: Facebook acadêmico?}

Quando atualizamos a nossa página no Currículo Lattes respondendo à pergunta " $O$ que você quer registrar?" é difícil não vir à memória a pergunta de outra rede social não tão diferente assim (Facebook): "O que você está fazendo agora?" Nas duas situações se faz importante observar a demanda por visibilidade. Não é suficiente ser o melhor, deve-se parecer ser o melhor. A internet passa a agenciar subjetividades com "novos modelos de escrita e expressão das individualidades", segundo Rosa e Zamora (2012, p.581)

Há a necessidade não só de estar fazendo algo, como de comunicar ao mundo público essa atividade, que parece só passar a existir nessa condição de publicizada. Essa observação foi adiantada já nos escritos de Debord, quando descreveu o que chamou de "sociedade de espetáculo”. O Lattes, assim como plataformas não acadêmicas como o Facebook, são profícuas vitrines de um eu em exposição, de um eu em competição performática pelo primeiro lugar em um ranking de vidas, pretensamente, Qualis A1.

Tais reflexões sobre a espetacularização da vida acadêmica já começam a ocupar alguns espaços nas discussões. Ainda que em lugares por muitos percebidos como periféricos. Tal como a pichação nas paredes do restaurante universitário de uma Universidade, que declarava: "Lattes que eu tô passando".

Costa (2004) fala de uma invisibilidade pública, que cursaria com a divisão do sujeito pelo trabalho que ele desempenha e não pelo seu real valor, pelo seu significado, enxerga-se o sujeito pela função que desempenha, mas não como pessoa. A sociedade atual é, em algumas de suas dimensões, pautada nas aparências e no benefício que as relações podem dar ao sujeito, mesmo que estes benefícios sejam oriundos de relações diretas ou não que as pessoas travem entre si.

A exposição nas redes sociais e das relações virtuais também influenciam fortemente nas relações que os indivíduos desenvolvem profissionalmente, o que quase sempre acaba por influenciar nas relações pessoais desses indivíduos. Sibilia (2008) faz em seus trabalhos uma

\section{POLÊM!CA | Revista Eletronica da Ueij}


análise de uma forma bem especifica de se conectar ao mundo, que seria a escrita de si, uma autobiografia que se torna antes de qualquer coisa rápida, instantânea, digital, multimídia.

A autora traz exemplos como Orkut, MySpace, os blogs e o próprio FaceBook, podemos incluir ainda, de forma específica, a crescente ascensão da Plataforma Lattes como sendo também um desses meios de "publicar" autobiografias profissionais, funcionando como vitrine, modo de se pôr em evidencia no mercado. Maneira que a sociedade contemporânea encontrou para legitimar a cultura de observação do outro e a superexposição de si como forma de comercialização de sua bagagem cientifica, acadêmica. Muito embora nem sempre essa se equipare à bagagem intelectual, crítica, reflexiva ou inovadora.

São requisitadas, cada vez mais, habilidades de autocomercialização e autopromoção, em uma subjetividade alter-dirigida (SIBÍLIA, 2008) que transforma intimidades em espetáculos e realidades em peças publicitárias. A exemplo do site e canal no You tube "Médico vencedor" que divulga, vende, estratégias de marketing digital que prometem não somente retorno financeiro, mas transformar o médico cliente no "Profissional \#l, o mais famoso da cidade"

Essa vitrine tão atual não demonstra ter espaço para os fracassos cotidianos ou os pontuais deslizes da vida de qualquer que seja o indivíduo. Não há espaço para o que seria o curriculum mortis, expressão cunhada por Konder (2008), para contrapor essa lógica que expõe apenas as vitórias e os momentos de glória, que esconde, mascara os momentos de erros, sejam erros acadêmicos, profissionais ou mesmo pessoais.

Konder (2008) cita de forma crítica o curriculum vitae, como uma ferramenta para potencializar as tensões internas dos indivíduos e obriga o sujeito a trajar-se de uma fantasia de suposto saber, que promove superioridades artificiais. Por conta de sua unilateralidade, a imagem de vitorioso que o sujeito tem de si acaba por empobrecer seu autoconhecimento e boicotar sua autocritica.

\section{"Pesquisador que só Lattes não morde"}

A provocação: "Pesquisador que só Lattes não morde", título de instigante ensaio de pesquisador da área de comunicação e cultura contemporânea (ROCHA, 2012) é mostra que algumas vozes lúcidas ainda conseguem ser ouvidas em seus veementes protestos contra as transformações por quais tem passado o mundo acadêmico. No entanto essas vozes têm

\section{POLÊM!CA | Revista Eletronica da ver}


encontrado poucos espaços de expressão. Apesar disso, a resistência criativa desenvolve possibilidades de reflexão usando metodologias como o humor. Esse é o caso de uma bem humorada crítica feita por um grupo que apresenta seu trabalho como "Jornalismo fictício contra-hegemônico. Hiperrealismo, quiçá.”. (VERAS, 2013)

Utilizando o artifício do humor, narram uma fictícia (?) nova patologia que viria se disseminando entre os universitários brasileiros, trataria da 'Sindrome Lattes", como sintomas listam: "Horas perdidas na Plataforma Lattes buscando o currículo dos amigos; • Locução constante sobre o próprio Lattes; - Narcisismo exacerbado acerca de comunicações apresentadas ou artigos escritos; - Exposição constante e angustiada nas redes sociais acerca dos próprios méritos; - Corrida ininterrupta por bolsas e viagens para congressos [cujos temas são risíveis]; - Esquecimento progressivo da cerveja, dos sorrisos, da família, dos amigos [concorrentes], do trivial e do motivo mesmo da doença: as pesquisas." (VERAS, 2013). Além do registro de atividades do cotidiano como eventos acadêmicos. Seria o caso de hipotético estudante, citado na reportagem,que ao vir de uma quermesse tradicional em sua cidade, teria registrado o evento como trabalho de campo de antropologia, somente confirmando o sintoma da semana anterior, quando teria doado sangue no Hospital da Beneficência Portuguesa e postado na plataforma lattes que tratava-se de participação em evento internacional!

Entretanto, Rocha (2012), que criou polêmica com sua citada assertiva "Pesquisador que Lattes não morde”, realça que "Pesquisador que morde, também Lattes”. Enfatizando que a reflexão crítica, também contida neste artigo, não busca atingir o instrumento currículo. Outrossim, os discursos gerados a respeito das formas de produzir pesquisa, conhecimento e reflexão na academia contemporânea. Discursos que alicerçam práticas que transformam o espaço do pensar crítico em lugar de reprodutibilidade esvaziada de algum sentido que não seja de mercado.

\section{Considerações Finais}

Sim, Universidade Sitiada.

Sitiada, palavra que tem como sinônimos: "cercada", "encurralada" e "assediada".

Palavra também usada por Clarice Lispector (2014) em seu livro Cidade Sitiada, romance em que a personagem Lucrécia tem sua consciência prejudicada pelo raciocínio

\section{POLÊM!CA | Revista Eletronica da Uej}


embotado. Réplica da Macabéa de "A hora da estrela", Lucrécia leva um viver cotidiano apático. Uma catatonia do pensamento a imobiliza na superfície e não permite mudanças de perspectivas.

Assim como no romance de Lispector, a universidade brasileira, emparedada, sucumbe à busca pela visibilidade cenográfica e performática. De onde antes víamos o brotar de novas possibilidades, vemos, sustentada também pelas agências de fomento e avaliação, a instalação de uma lógica de mercado que segue na contramão do pensar.

Diante do exposto, há muita pertinência no questionamento de Sevcenko (2001, p.92) "cada vez mais eu sinto que quero morar num grande aqui e num longo agora" sinalizando o oposto de sua percepção: o fato de que somos dragados cada vez mais rápido e mais fundo para um mundo retraído num pequeno aqui e num curto agora.

Assim, é imprescindível nos perguntarmos: Diante do que está sendo escolhido para ser visibilizado, o que está sendo sombreado?

\section{Referências}

BENDASSOLLI, P. F. Cultura da performance. Revista GV Executivo, vol. 3, n.4, p.45-48, 2004.

BIRMAN, J. (2010). Muitas felicidades?! O imperativo de ser feliz na contemporaneidade. In: FREIRE FILHO, J. (org.). Ser feliz hoje: reflexões sobre o imperativo da felicidade. Rio de Janeiro: Editora FGV, 2010, p.27-48.

CHAUÍ, M. Contra a Universidade Operacional. Rio de Janeiro: Museu da vida/Fiocruz, 2015 (Comunicação oral). Disponível em: 〈https://youtu.be/TNQg95QIvsQ>. Acesso em: 05 mai de 2015.

COSTA, F. B. Homens invisíveis: relatos de uma humilhação social. São Paulo: Editora Globo, 2004.

EHRENBERG, A. O culto da performance: da aventura empreendedora à depressão nervosa. São Paulo: Editora Idéias\&Letras, 2010.

KONDER, L. O curriculum mortis e a reabilitação da autocrítica. Disponível em: <http://laurocampos.org.br/2008/02/o-curriculum-mortis-e-a-reabilitacao-da-autocritica/ >. Acesso em: 12 jun. 2015.

LISPECTOR, C. Cidade Sitiada. Rio de Janeiro: Rocco, 2014.

MOSKOWITZ, E. S. In therapy we trust: America's obsession with self fulfillment. Baltimore: The John Hopkins University Press, 2001.

ROCHA, T. Pesquisador que só Lattes, não morde. Comunicação \& Política. 07 fev. de 2012. Disponível em: $<$ http://comunicacaoepolitica.com.br/blog/2012/02/pesquisador-que-so-lattes-nao-morde/>. Acesso em: 10 mai de 2015

ROSA, C.M.; ZAMORA, M. H. Usos da internet: algumas reflexões ético-políticas. Polêm!ca.,v. 11, n. 4 , out/dez 2012.

\section{POLÊM!CA | Revista Eetrônica da veri}


SEVCENKO, N. A corrida para o século XXI: no loop da montanha-russa. São Paulo: Companhia das Letras, 2001.

SIBILIA, P. O artista como performer: Dilemas do eu espetacular nas artes contemporâneas. In: LABRA, Daniela (Org.). Performance Presente Futuro, vol. II. Rio de Janeiro: Ed. Aeroplano e Oi Futuro, 2010, p.1420.

SIBILIA, Paula. O show do eu: a intimidade como espetáculo. Rio de Janeiro: Nova Fronteira, 2008.

VERAS, H. Estudante é internado após inserir no Currículo Lattes uma participação em quermesse. Diário pernambucano. 10 jun. 2013. Disponível em: <http://www.diariopernambucano.com.br/noticias/estudante-einternado-apos-inserir-no-curriculo-lattes-uma-participacao-em-quermesse/>. Acesso em: 01 mai. 2015.

VERAS, L.; ROSA, C. M. Vale quanto compra: consumo, contemporaneidade e subjetividade. Revista FSA, v. 12, n.3, p. 215-231, 2015.

Recebido em: 02/07/2015.

Aceito em: 23/07/2015. 